\title{
Confusion and paranoia associated with oral tocainide
}

\author{
C.W.F. Clarke* and E.O. El-Mahdi \\ Departments of Medicine, Burton Road Hospital and the Guest Hospital, Dudley, West Midlands, UK.
}

\begin{abstract}
Summary: Two middle aged female patients developed hallucinations and severe confusion with paranoid features during oral tocainide administration at recommended dosage levels. Both patients had evidence of impaired renal function. Symptoms were provoked on re-challenge in the first patient. In the second patient the tocainide blood level was higher than the recommended therapeutic range. Both patients reverted to their normal mental state on withdrawal of the drug.
\end{abstract}

\section{Introduction}

Confusion is a well recognized side effect of intravenous lignocaine and other similar membrane active anti-arrhythmic agents. Tocainide, an analogue of lignocaine, is available in intravenous and oral preparations and is indicated in the treatment of acute and chronic ventricular arrhythmias. Reports on the central nervous system effects of oral tocainide are limited. We wish to report two cases of severe confusion with paranoid features which followed oral tocainide administration.

\section{Case reports}

\section{Case 1}

A 58 year old female was admitted with acute bronchial asthma and left ventricular failure associated with aortic valve disease. She had multiple ventricular ectopics despite regular treatment with oral disopyramide. She was treated with parenteral hydrocortisone, nebulized salbutamol and oral frusemide.

Twelve days after admission she developed ventricular fibrillation which responded to direct current shock and intravenous lignocaine. Disopyramide was discontinued and lignocaine was replaced, $48 \mathrm{~h}$ later, with oral tocainide $400 \mathrm{mg} 8$ hourly. Persistence of multiple ventricular ectopics 3 days later prompted an increase of tocainide to $600 \mathrm{mg} 8$ hourly. At this stage she was well and her mental state was normal. Seventeen hours later she became markedly confused, afraid and suspicious of staff members and other

C.W.F. Clarke, F.R.C.P. (Glasg) and E.O. El-Mahdi, M.R.C.P. (UK)

*Present address: Russells Hall Hospital, Dudley, W. Midlands.

Accepted: 23 November 1983 patients. She also had visual and auditory hallucinations involving death and burials. These symptoms persisted for $40 \mathrm{~h}$ and disappeared completely $36 \mathrm{~h}$ after stopping tocainide. No other medication had been changed.

Eight days later she was challenged with 8 hourly doses of lactose in gelatine capsules. There were no ill effects and on the 5th day identical capsules containing $600 \mathrm{mg}$ tocainide were substituted for the placebo without the patient's knowledge. Two days later she became mildly confused and suspicious and refused further medication. These symptoms disappeared within $10 \mathrm{~h}$ of discontinuing tocainide. During 6 months of follow-up her mental state has remained normal.

\section{Case 2}

A 52 year old female with a history of myocardial infarction was admitted with congestive cardiac failure and right lower lobe pneumonia. She improved with diuretics and antibiotics. She had for 7 months been on oral mexiletine for the treatment of multiple ventricular ectopics. She associated epigastric discomfort with mexiletine which was then stopped and oral disopyramide was started. Five days later an attack of ventricular tachycardia was treated by cardioversion and intravenous lignocaine. Disopyramide was discontinued. Two days after the replacement of intravenous lignocaine by oral tocainide $400 \mathrm{mg} 8$ hourly, she became severely confused and paranoid. She had visual and auditory hallucinations of a religious type. Tocainide was discontinued and within $30 \mathrm{~h}$ her mental state returned to normal. Thirteen hours after the last dose her blood tocainide level was $49.5 \mu \mathrm{mol} / 1$ (therapeutic range $18-45 \mu \mathrm{mol} / \mathrm{l}$ ). During 6 months of follow up her mental state has remained normal.

(C) The Fellowship of Postgraduate Medicine, 1985 


\section{Discussion}

Tocainide is structurally related to lignocaine and differs from it in being methyl substituted on the side chain and lacking 2 ethyl groups (Figure 1). Unlike lignocaine, tocainide does not undergo rapid first pass metabolism in the liver and is, therefore, suitable for oral administration.

Confusion is a recognized side effect of intravenous lignocaine. Experience with oral tocainide is limited and the manufacturers' data mentions the most frequent central nervous system side effects as paraesthesia, tremors, sensations of heat and cold, dizziness and light headedness.

Fifteen of the 369 patients entered into the American tocainide emergency use programme developed confusion. It was noted that adverse experiences with tocainide were primarily neurological and gastrointestinal in nature and were transient and reversible (Horn et al., 1980). In a study of 30 patients with refractory ventricular arrhythmias treated with oral tocainide, one patient experienced delusions and thought impairment (Ryan et al., 1979). In another study of the effect of oral tocainide on refractory ventricular arrhythmias accompanying myocardial infarction, one patient developed confusion and paranoia (Haffajee et al., 1980). One case of severe paranoia associated with concomitant tocainide and propranolol treatment was reported in detail (Rubino and Jackson, 1982). In their case, the patient had been on a large dose of oral tocainide ( $800 \mathrm{mg} 8$ hourly)

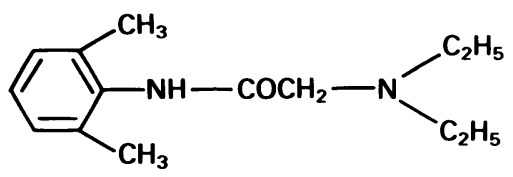

Lignocaine

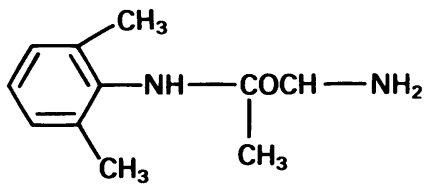

Tocainide (2-amino-2, 6-propionoxylidide) without showing any side effects, but when propranolol was added to his treatment, on two separate occasions, he became severely confused and paranoid. The serum tocainide levels on both occasions were within the therapeutic range. The authors could not attribute the symptoms to either of the drugs and they suggested that the combination of tocainide and propranolol may have an additive or possibly a synergistic effect producing behavioural changes.

In our first case confusion and paranoia developed $16 \mathrm{~h}$ after increasing the dose of tocainide to $600 \mathrm{mg} 8$ hourly. The reappearance of symptoms of confusion following a single blind re-challenge with the drug confirmed the association with tocainide. Blood tocainide levels were not done. In Case 2 the $13 \mathrm{~h}$ plasma tocainide level was higher than the therapeutic range of $18-45 \mu \mathrm{mol} / 1$.

In both cases the plasma urea concentrations were elevated to 10.4 and $11.4 \mathrm{mmol} / \mathrm{l}$ respectively at the time of tocainide treatment (normal range 2.5 to $6.5 \mathrm{mmol} / \mathrm{l}$ ). Although $40 \%$ of tocainide is excreted unchanged in the urine, the manufacturers do not recommend dosage adjustments in mild to moderate renal dysfunction. Mental symptoms in these patients might well have been precipitated by high plasma drug levels following drug accumulation, as shown in Case 2. It is well documented that the plasma half-life of tocainide is $12-15 \mathrm{~h}$ and Graffner (1979) showed thaf 8 hourly administration of tocainide would result in drug levels of about 2.5-3.0 times higher than after single dose. Boyes et al. (1979) noted that when centraf nervous system symptoms developed after intravenous loading doses of tocainide, blood levels exceeded $78 \mu \mathrm{mol} / \mathrm{l}$.

The mental symptoms were strikingly similar in our two cases and were characterized by fear, suspicion and visual and auditory hallucinations of a religious nature. Complete reversion to normal mental states followed the discontinuation of tocainide in both cases.

These cases suggest that oral tocainide can cause confusion and paranoia when given in the recommended dosage to patients with impaired renal function. This may be due to accumulation of the drug to levels above the therapeutic range.

We suggest that dosage adjustment based on tocainide blood levels should be an important aspect of the management of patients with impaired renal function who are treated with oral tocainide.

Figure 1 Structural relationship of lignocaine and tocainide 


\section{References}

BOYES, R.N., MEYER, M.B., HUTTON, I. \& TWEDDEL, A. (1979). Tocainide blood levels in patients following intravenous and oral administration. Workshop on Tocainide. Pottage, A. and Ryden, L. (Eds) pp. 105-108. A.B. Hässle, Sweden.

GRAFFNER, C. (1979). Tocainide pharmacokinetics: Absorption, Metabolism, Excretion. Workshop on Tocainide. Pottage, A. and Ryden, L. (Eds), pp. 90-99. A.B. Hässle, Sweden.

HAFFAJEE, C.I., ALPERT, J.S. \& DALEN, J.E. (1980). Tocainide for refractory ventricular arrhythmias of myocardial infarction. American Heart Journal, 100, 1013.
HORN, H.R., HADIDIAN, Z., JOHNSON, J.L., VASSALLO, H.G., WILLIAMS, J.H. \& YOUNG, D. (1980). Safety evaluation of tocainide in American Emergency Use Programme, American Heart Journal, 100, 1037.

RUBINO, M. \& JACKSON, E. (1982). Severe paranoia with concomitant tocainide and propranolol therapy. Clinical Pharmacy, 1, 177.

RYAN, W., ENGLER, R., LeWINTER, M. \& KARLINER, J.S. (1979). Efficacy of a new oral agent (tocainide) in the acute treatment of refractory ventricular arrhythmias, American Journal of Cardiology, 43, 285. 